\title{
Simple Fundamentals of Logic
}

\author{
Zekai Şen ${ }^{1}$
}

Prof. Dr., Istanbul Medipol University, Engineering and Natural Sciences Faculty, Istanbul, Turkey

ORCID: Z.Ş. 0000-0001-8926-1247

Sorumlu yazar/Corresponding author: Zekai Şen,

Istanbul Medipol University, Engineering and Natural Sciences Faculty, Istanbul, Turkey

E-mail/E-posta: zsen@medipol.edu.tr

Başvuru/Submitted: 18.11.2019 Revizyon Talebi/Revision Requested: 08.12.2019

Son Revizyon/Last Revision Received:

11.12.2019

Kabul/Accepted: 13.12 .2019

\section{Atıf/Citation:}

Sen, Zekai. (2019). "Simple Fundamentals of Logic" Felsefe Arkivi-Archives of Philosophy, 51:331-334.

https://doi.org/10.26650/arcp2019-5124

\section{ABSTRACT}

For the most part, contemporary logicians discuss previous logicians' ideas from different civilizations and make comments thereon, thus addressing specialists in logic studies. In many education systems, the science philosophy and logic principles do not play a preliminary role. Today, in many education systems the science of philosophical thinking and logic principles should play a preliminary role for rational inferences. Unfortunately, in education systems there is little formal training about the principles of logic and their extraordinary capacity to sharpen the mind with brain experiments, which leads to the attaining of innovative ideas. This is the case especially in engineering institutions, where the students are fed with various mathematical principles, equations and numerical solution methodologies. Although classically almost everybody states that mathematics is based on logic, logical principles are not thought through systematically in education systems. . In this short paper the main purpose is to mention $t$ the logical principles that should be beneficial to the young generation, regardless of whether the interest is in logical sciences or in basic works to arrive at limitless logical conclusions.

Keywords: Education, inference, logic, rationality, young 


\section{Introduction}

Although logic is a subdivision of philosophy due to its importance in scientific inferences it has its own status and importance in any reasoning for final decision making. Logic is the search for rational formal a priori truth, especially through mathematics, which helps to develop construction and exploitation of abstract or mathematical models. Practical and pure logical principles play an emphatic role at the very bottom of mathematical modeling and computer software for rapid, reliable and valid engineering problem solutions. The intellectual content of engineering can be enhanced after philosophical thinking by means of logic rules and principles. Software supporting these intellectual activities is more effective when it is built on solid logical foundations. Scientific and engineering revolutions can be achieved after effective application of logic rules. An increasing rate of logical revolutions is expected in the future. In order to take their place among such innovative studies logic rules must be deduced for more effective manipulation of knowledge and information. Reasoning tasks can be achieved by good formal language, whereby "formal language" has precise syntax and semantics. Reasoning tasks are important when there are inferences and hence a further condition is required on our notion of formal language, namely it should provide a calculus defining some kind of consequence relation (Şen, 2014).

The fundamentals of logic can be learned from a book by the author Ural (2011), which provides logical prepositions and inference systems in detail. The book is based on Aristotalian logic, which is crisp, i.e. two-valued as an object and its opposite without inclusion of the third alternative in between.

The main purpose of this manuscript is to present rather simple fundamentals of logical thinking and inference conclusions in daily life. The sequence of this manuscript includes philosophy, logical inference, shape (Cartesian coordinate system) and finally the mathematical arena, as the end product. Critiques could question how mathematical education systems can be successful without philosophical and particularly logical principles.

\section{Basic Simple Principles}

In order to put logic into practice simply, there are two principles that are fundamental, which are available to any individual from birth, of course after a certain age. Anybody is capable of making a comparison between two things or variables even without having any background knowledge. One is not able to compare more than two things simulateneously, but simultaneous comparison is possible between two variables. These two principles appear in the forms of questions, which are:

1) What is the relationship between two variables? The answer may be in the form of "directly proportional" or "indirectly proportionsl" or one may not logically see such relationships in which case one will need to consult experiments either in a laboratory or measurements in nature, 
2) Is the relationship linear (or non-linear) is the second question to be answered. Most of the time, one is capable of producing linear visualization or its non-linear alternative.

The answers to these two questions bring four alternatives to a sane person as in Figure 1, as directly-proportional and linear, or indirectly proportional and linear, or directly proportional and non-linear, or inversely proportional and non-linear.

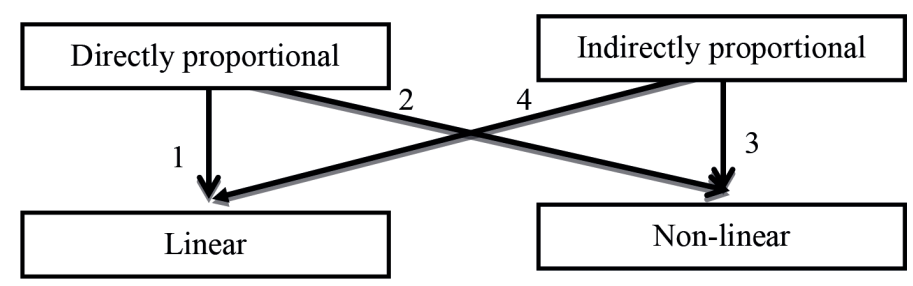

Figure 1. Basic Logical Combinations

A simple example for logical inference is to search for the relationship between the alcohol level and the possibility of accident risk. It is well understood with approximate reasoning that there is a direct relationship between these two variables. The answer to the next question is whether it is linear or non-linear. Logical thinking does not allow unbounded alcohol intake and there is a limit, and accordingly the relationship is non-linear. After these two conclusions, their combination on a Cartesian coordinate system appears as in Figure 2.

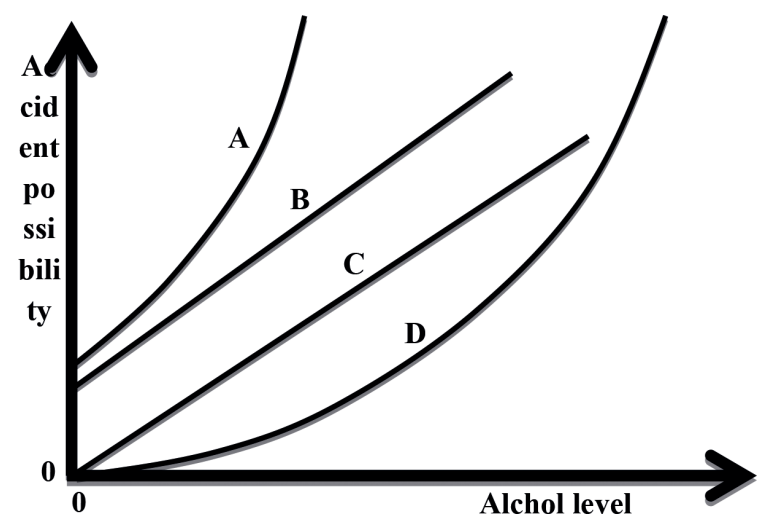

Figure 2. Alcohol Level and Accident Possibility Relationship

Further logical ponderances are necessary to identify which one of these alternatives is the most suitable solution for the question at hand. Is it possible that those who do not drink alcohol do not cause accidents? The answer is no, and this answer gives the impression that the representative solution cannot pass through the origin, and consequently $\mathrm{C}$ and $\mathrm{D}$ cannot be solutions, because they pass from the origin. The only solution as directly proportional and nonlinear is the A alternative. 
After all that has been explained above one can draw the flow chart of this procedure as in Figure 3.

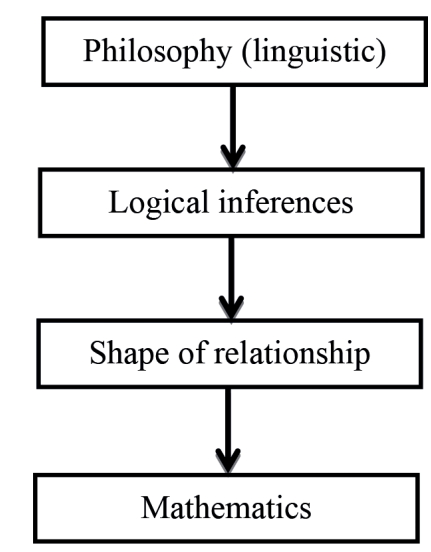

Figure 3. Sequential Arrival to Mathematics

The first step is linguistical visualization of the phenomenon concerned in the mind, which is philosophical thinking. The second step is the logical inference as explained above. The third step represents the shape inference as in Figure 3, and finally one arrives at the stage of mathematics, which is based on symbolic logic.

\section{Conclusions and Recommendations}

Logic is the main driving force towards rational thinking after a set of approximate reasoning about any phenomenon of concern. Its teaching even at secondary school level is essential for better and enlightened training of individuals. In this short paper the simple basics of logic are explained through an example, which is indicated in the sequence of steps namely philosophical thinking, logical inferences, Coordinate axes drawings such as shapes, reasoning and, finally, reaching to the stage of Mathematics. From these explanations one can understand that mathematical teaching without logical inferences and shape conversions leaves the learning domain to mechanical grasp, and mindless memorization. Finally, the reader should also try to learn fuzzy logic, which is more natural than crisp and symbolic logic principles.

\section{References}

Ural, Ş., (2011). Temel Mantık, (genişletilmiş III. Baskı), Çantay Kitabevi, 2011.

Şen, Z., (2014). Philosophical, Logical and Scientific Perspectives in Engineering, Springer, 260 pp. 